\title{
Evaluation of Targeted Therapy for Locally Advanced or Metastatic Renal Cell Carcinoma in Tunisia
}

\author{
Khaled Ben Ahmed ${ }^{*}$, Amira Daldoul ${ }^{2}$, Ghassen Tlili1, Laila Ben Fatma², Olfa Gharbi2, \\ Mahdi Afrit ${ }^{3}$, Jihene Fkih ${ }^{4}$, Hammouda Boussen' ${ }^{3}$ Mounir Frikha', Faouzi Mosbah"1, \\ Slim Ben Ahmed ${ }^{2}$ \\ ${ }^{1}$ Department of Urology, Sahloul University Hospital, Sousse, Tunisia \\ ${ }^{2}$ Department of Medical Oncology, Farhat Hached University Hospital, Sousse, Tunisia \\ ${ }^{3}$ Department of Medical Oncology, Abderrahman Mami University Hospital, Ariana, Tunisia \\ ${ }^{4}$ Department of Medical Oncology, Habib Bourguiba University Hospital, Sfax, Tunisia \\ Email: "khaledbahmed@hotmail.com
}

Received 16 April 2016; accepted 24 July 2016; published 27 July 2016

Copyright (C) 2016 by authors and Scientific Research Publishing Inc.

This work is licensed under the Creative Commons Attribution International License (CC BY). http://creativecommons.org/licenses/by/4.0/

c) (i) Open Access

\section{Abstract}

Introduction: Renal cell carcinoma (RCC) is known to be chemo resistant but with the introduction of targeted therapies; there has been a "revolution" in its treatment strategies. The only targeted therapy available in Tunisia for the treatment of metastatic and/or locally advanced RCC is sunitinib. Objective of the Study: To evaluate therapeutic results and tolerance of sunitinib in metastatic and/or locally advanced RCC. Subjects and Methods: This was a retrospective study covering a period of six years (from January 2008 to January 2014) conducted in 5 medical oncology departments in Tunisia. The population of the study consisted of 29 patients treated with sunitinib for metastatic and/or locally advanced RCC. Results: The mean age of patients was 51 years. Three patients had tumor recurrence and 26 patients had a metastatic RCC. The prognosis was good for 5 patients, intermediate for 19 patients and poor for 5 patients. The median duration of treatment was 5 months. Because of side effects, treatment was discontinued in $12.5 \%$ of cases and the dose was reduced in $\mathbf{1 0 . 3 \%}$ of cases. Side effects consisted of asthenia $(95.8 \%)$, stomatitis $(\mathbf{7 0 . 8 \% )}$, anemia (50\%), hand-foot syndrome $(55.8 \%)$ in addition to nausea and vomiting $(54.2 \%)$. Objective response was observed in $37.5 \%$ of patients after 3 months of treatment and in $50 \%$ after 6 months. The median progression-free survival was 14 months $(95 \% \mathrm{CI}, 7.9$ to 20.6$)$. The median overall survival was 22 months $(95 \% \mathrm{CI}, 15.6$ to 28.7$)$. Conclusion: The prognosis of RCC in Tunisian patients has clearly improved with the introduction of sunitinib, but other therapies with a proven efficacy as a first and second line therapy should be considered.

*Corresponding author.

How to cite this paper: Ahmed, K.B., Daldoul, A., Tlili, G., Fatma, L.B., Gharbi, O., Afrit, M., Fkih, J., Boussen, H., Frikha, M., Mosbah, F. and Ahmed, S.B. (2016) Evaluation of Targeted Therapy for Locally Advanced or Metastatic Renal Cell Carcinoma in Tunisia. Open Journal of Gastroenterology, 6, 197-204. http://dx.doi.org/10.4236/ojgas.2016.67025 


\section{Keywords}

\section{Renal Cell Carcinoma, Metastasis, Molecular Targeted Therapy, Sunitinib, Drug Tolerance}

\section{Introduction}

Renal cell carcinoma (RCC) accounts for 3\% of all cancers worldwide and clear cell carcinoma (CCC) represents its most common type. More than $30 \%$ of RCC are metastatic and $40 \%$ of patients with RCC relapse after treatment. The results of medical treatment of RCC have however improved with the introduction of targeted therapies. Therefore, Tunisian health authorities have approved, since 2009, the use of sunitinib for the treatment of locally advanced and/or metastatic RCC (mRCC). To this date, there was no previous multicentric national study investigating the use of sunitinib in Tunisia.

The objective of this study was to evaluate the efficacy and the tolerance of sunitinib in Tunisian patients with RCC.

\section{Subjects and Methods}

Twenty nine patients with advanced or mRCC were treated by sunitinib in 5 medical oncology departments in Tunisia (Sousse, Monastir, Ariana, Tunis, Sfax) from January 2008 to January 2014. Update of data was performed in 15 April 2014. Patients' medical history, radiological characteristics and surgical management were collected.

Sunitinib was administered orally at a dose of $50 \mathrm{mg}$ daily, during 4 weeks of treatment followed by a 2-week rest period, in cycles of 6 weeks. A dose reduction of sunitinib was allowed depending on the toxic event's type and severity. To evaluate sunitinib efficacy, computed tomography was performed at the beginning and during treatment. According to Choi criteria, partial response (PR) was defined as a decrease $\geq 10 \%$ in size or $\geq 15 \%$ in attenuation.

The SPSS software was used for statistical analysis. Overall survival (OS) was measured from the date of treatment beginning until death due to any cause. Progression-free survival (PFS) was measured from the date of treatment beginning until tumor progression.

\section{Results}

The patients' mean age was 51 years (ranging from 24 to 73 years) and the male to female sex-ratio was 4 to 1 . Twenty six patients had a nephrectomy while the diagnosis for the 3 remaining patients was made by percutaneous biopsy. The type was CCC in $80 \%$ of cases and the distribution among I, II, III, and IV grades of Führman was respectively $0.07 \%, 13.8 \%, 41.37 \%$ and $24.13 \%$ while the grade was unmentioned in $13.8 \%$ of cases. At initial presentation, TNM 2009 stage distribution was as follow: stage II, $n=5(17.2 \%)$; stage III, $n=10$ (34.5\%); stage IV, $n=14$ (48.3\%). Three patients had tumor recurrence and 26 patients were diagnosed with metastases (Table 1).

At initial presentation, approximately $51 \%$ of patients had synchronous metastases while $41 \%$ of patients developed metachronous metastases (Table 2). The median time to relapse after nephrectomy was 15 months (ranging from 3 to 43 months). Sixty-two percent of patients were classified as belonging to the intermediaterisk group according to MSKCC score (Table 3). The median duration of treatment was 5 months (ranging from 1 to 16 months). A total of $12.5 \%$ of patients had drug interruption because of adverse events (AE), whereas $10.3 \%$ had a dose reduction.

Therapeutic results were reported for only 24 patients who were eligible for the final evaluation. Sunitinibtreatment was associated with $37.5 \%$ of objective response rate (ORR) after 3 months and $50 \%$ after 6 months (Table 4). Median PFS was 14 months (95\% confidence interval (CI), [7.9 to 20.6]) (Figure 1) and median OS was 22 months (95\% CI, [15.6 to 28.7]) (Figure 2). Side effects related to sunitinb are reported in Table 4. Fatigue was the most frequent related side effects, occurring in more than $90 \%$ of cases, and was severe (grade 3 ) in $4.2 \%$ of cases. Anorexia was reported in $50 \%$ of patients but did not exceed grade 2. Diarrhea was reported in approximately $29.2 \%$ of patients. Vomiting and nausea occurred in more than $50 \%$ of patients but grade 3 was 
Table 1. Characteristics of patients treated with sunitinib.

\begin{tabular}{|c|c|c|}
\hline & Number & Percentage \\
\hline \multicolumn{3}{|l|}{ Age (years) } \\
\hline$<30$ & 2 & $6.9 \%$ \\
\hline$[30-40]$ & 3 & $10.3 \%$ \\
\hline$[40-50]$ & 7 & $24.1 \%$ \\
\hline$[50-60]$ & 11 & $37.9 \%$ \\
\hline$[60-70]$ & 4 & $13.8 \%$ \\
\hline$>70$ & 2 & $6.9 \%$ \\
\hline \multicolumn{3}{|l|}{ Sex } \\
\hline Male & 22 & $75.9 \%$ \\
\hline Female & 7 & $24.1 \%$ \\
\hline \multicolumn{3}{|l|}{ TNM Stage } \\
\hline II & 5 & $17.2 \%$ \\
\hline III & 10 & $34.5 \%$ \\
\hline IV & 14 & $48.3 \%$ \\
\hline \multicolumn{3}{|l|}{ Histological type } \\
\hline Clear cell carcinoma & 23 & $79.3 \%$ \\
\hline Papillary carcinoma & 5 & $17.2 \%$ \\
\hline chromophobe & 1 & $3.4 \%$ \\
\hline \multicolumn{3}{|l|}{ Fuhrman Grade } \\
\hline I & 2 & $6.9 \%$ \\
\hline II & 4 & $13.8 \%$ \\
\hline III & 12 & $41.4 \%$ \\
\hline IV & 7 & $24.1 \%$ \\
\hline Not mentioned & 4 & $13.8 \%$ \\
\hline
\end{tabular}

Table 2. Distribution of patients according to metastatic sites.

\begin{tabular}{ccc}
\hline Metastasis & Number & Percentage \\
Lung & 10 & $38.5 \%$ \\
Liver & 4 & $15.4 \%$ \\
Lung and Liver & 1 & $3.8 \%$ \\
Lung + peritoneal carcinomatosis & 1 & $3.8 \%$ \\
Bones & 2 & $7.7 \%$ \\
Liver + bones & 3 & $11.5 \%$ \\
Lung + bones + liver & 1 & $3.8 \%$ \\
Lung + bones + suprarenal gland & 1 & $3.8 \%$ \\
Small intestine & 1 & $3.8 \%$ \\
Mediastinum & 2 & $7.7 \%$ \\
Total & 26 & $100.0 \%$ \\
\hline
\end{tabular}


Table 3. Distribution of patients according to MSKCC risk.

\begin{tabular}{ccc}
\hline MSKCC risk & Number & Percentage \\
\hline Favorable & 7 & $24.1 \%$ \\
Intermediate & 18 & $62.1 \%$ \\
Poor & 4 & $13.8 \%$ \\
Total & 29 & $100.0 \%$ \\
\hline
\end{tabular}

Table 4. Distribution of patients according to response to treatment.

\begin{tabular}{ccc}
\hline Response at 3 months & Number & Percentage \\
PR & 9 & $37.5 \%$ \\
Stabilisation & 6 & $25.0 \%$ \\
Progression & 9 & $37.5 \%$ \\
Response at 6 months & 1 & $7.1 \%$ \\
CR & $1 \% 2.9 \%$ \\
PR & 6 & $14.3 \%$ \\
Stabilisation & 2 & $35.7 \%$ \\
Progression & 5 & $14.3 \%$ \\
Response at 9 months & & $42.8 \%$ \\
CR & 1 & $14.3 \%$ \\
PR & 3 & $28.6 \%$ \\
Stabilisation & 1 & $2 \%$ \\
Progression & 2 & \\
\hline
\end{tabular}

PR: partial response, CR: complete response.

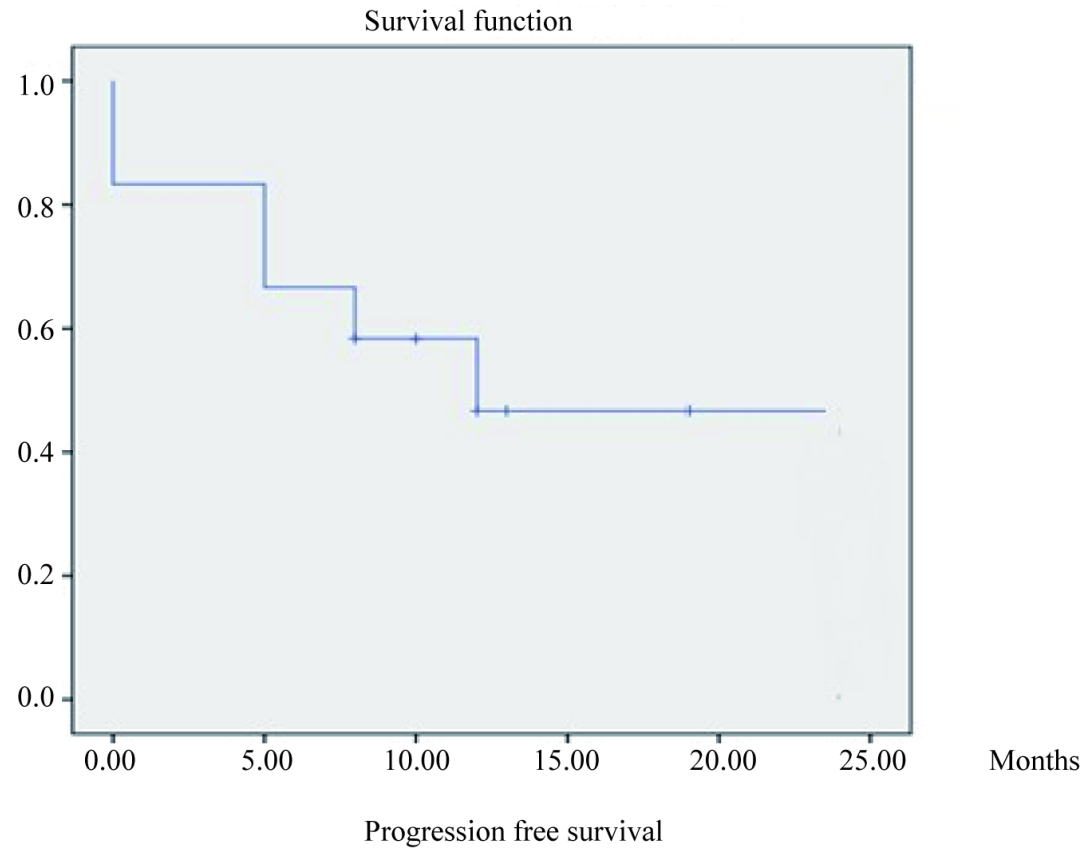

Figure 1. Progression-free survival Curve. 


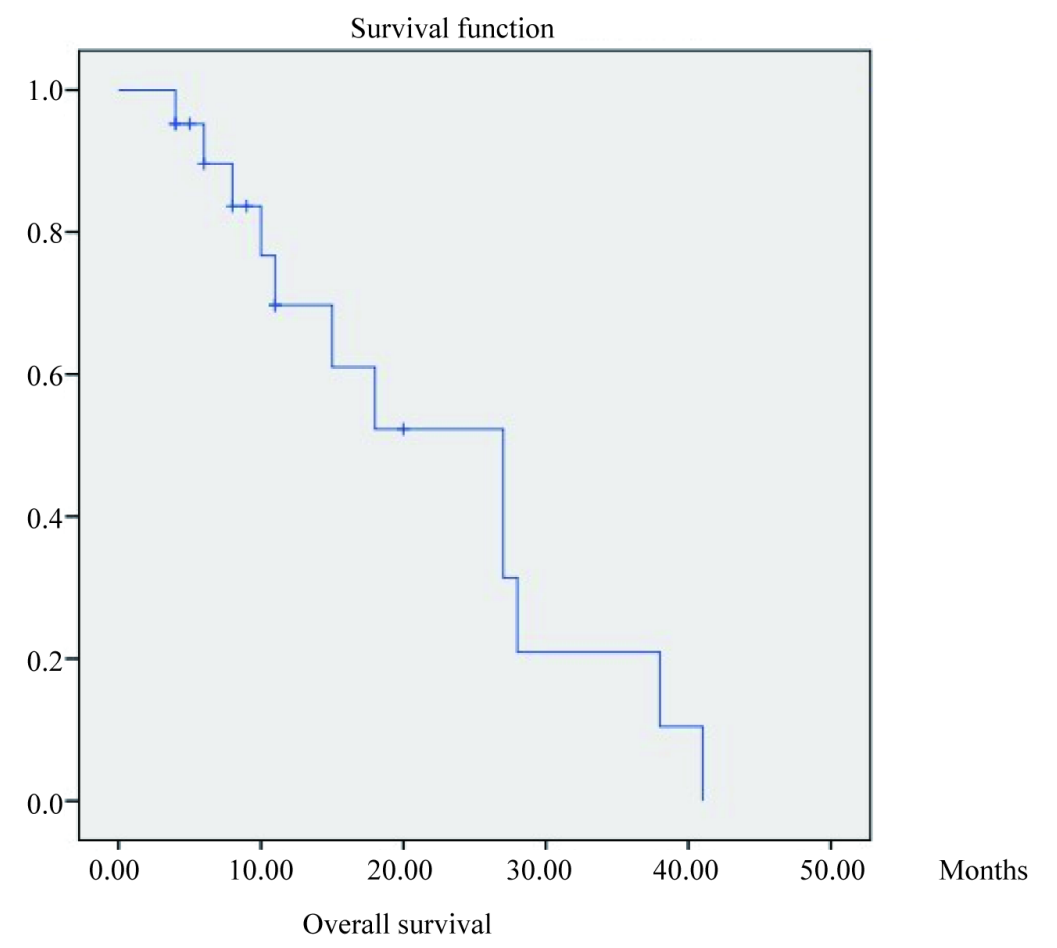

\section{Figure 2. Overall survival Curve.}

rare (less than 5\%). Encountered hematological disturbances were anemia (50\%), thrombocytopenia (25\%) and leucopenia (16.7\%). Oral changes, including taste changes and stomatitis, occurred with varying frequency (33\% - 70\%), but grade 3 toxicity was relatively rare (4.2\%). Skin changes were also reported, such as hand-foot syndrome (HFS) (55.8\%), changes in hair color (12.5\%), skin rash (12.5\%), skin depigmentation (12.5\%) and subungual splinter hemorrhages (12.5\%). Hypertension was reported in $33.4 \%$ of cases (Table 5).

\section{Discussion}

RCC is often diagnosed among patients aged over 60 years. Nevertheless, it can be seen in patients aged around 40 years, and more rarely in those under 40 (1). RCC affects mainly men and the global male/female ratio is estimated to range between 1.5 and 3 [1] [2]. Metastatic disease is a common situation, in fact $10 \%$ to $40 \%$ of patients are immediately metastatic at diagnosis [3]. In addition, 10 to $30 \%$ of patients develop metachronous metastases within an average time of 36 months [4] [5]. The CCC is the most frequent histological type ( $80 \%$ of cases) [3]. It is also the histological subtype responsible for the majority of metastases [6]. The tubulopapillar carcinoma and chromophobe carcinoma account for respectively $15 \%$ and $5 \%$ of histological types of RCC, leading to only 4 and $2 \%$ of metastatic cases [7].

For locally advanced tumors regardless of classification (T3 or T4, N0, N1, N2, M0, with or without vena caval thrombosis), surgery is performed with a curative intent, especially if surgical margins are negative [8]. Radical nephrectomy is recommended whenever age, co-morbidities, absence of metastases and resectability permit. Negative margins are a major prognostic factor for better outcome [9]. Lymph node dissection does not appear to influence the prognosis of RCC [10].

Before the advent of anti-angiogenic therapy, nephrectomy was recommended in patients whose prognosis is good or intermediate (according to MSKCC score) or when the tumor is symptomatic before starting systemic treatment [11]. In order to better elucidate this issue, several trials are currently underway. The 2 major trials are the Carmena trial, comparing nephrectomy combined with antiangiogenic versus antiangiogenic without nephrectomy [12], and the SURTIME EORTC trial, comparing nephrectomy in patients responding to Sunitinib versus nephrectomy followed by sunitinib. Currently, surgery keeps its place in the treatment of metastatic renal cancer in particular for the resection of the primary tumor, but also when metastases are resectable [13]. In addition to these indications, the standard treatment is based on antiangiogenic. 
Table 5. Distribution of patients by side effects of sunitinib.

\begin{tabular}{ccccc}
\hline Side effects & All grade & Percentage & Grade 3 - 4 & Percentage \\
Fatigue & 23 & $95.8 \%$ & 1 & $4.2 \%$ \\
Anemia & 12 & $50 \%$ & 0 & 0 \\
Leucocytopenia & 4 & $16.7 \%$ & 0 & 0 \\
Thrombocytopenia & 6 & $25 \%$ & 0 & 0 \\
Anorexia & 12 & $50 \%$ & 0 & 0 \\
Diarrhea & 7 & $29.2 \%$ & 0 & $4.2 \%$ \\
Nausea & 13 & $54.2 \%$ & 1 & $4.2 \%$ \\
Vomiting & 13 & $54.2 \%$ & 1 & $4.2 \%$ \\
Abdominal pain & 10 & $41.7 \%$ & 1 & 0 \\
Stomatitis & 17 & $70.8 \%$ & 0 & $4.2 \%$ \\
Taste changes & 8 & $33.3 \%$ & 1 & $4.2 \%$ \\
Hand-foot Syndrome & 11 & $55.8 \%$ & 1 & 0 \\
Skin rash & 3 & $12.5 \%$ & 0 & 0 \\
Skin discoloration & 3 & $12.5 \%$ & $12.5 \%$ & 0 \\
Subungual splinter hemorrhages & 3 & $33.4 \%$ & 0 & 0 \\
Hypertension & 8 & $70.3 \%$ & 0 & 0 \\
Arthralgia & 17 & $25 \%$ & 0 & 0 \\
Hepatotoxicity & 6 & & 0 \\
\hline
\end{tabular}

In this study, one patient received radio frequency for a single lung metastasis. Indeed, the radio frequency is a technique that has proven its efficacy in the treatment of unresectable pulmonary lesions, measuring less than 3 centimeter and being at some distance from vessels. Several studies have shown the efficacy of radiofrequency in the treatment of pulmonary metastases from colorectal carcinoma [14] [15] but there are no studies including large series regarding the lung metastases of mRCC [16].

The Sunitinib is a multi-target inhibitor of tyrosine kinases that has proven its superiority to INF $\alpha$ as a first line treatment for mRCC with good and intermediate prognosis. This was done during phase III in a randomized trial involving 750 patients. The primary endpoint was PFS and secondary endpoints were OS, tolerance and quality of life [17] [18]. This trial met its primary endpoint [17].

In Tunisia, sunitinib got his marketing authorization in 2009 with no specification about prognostic groups. It is still until nowadays the only targeted therapy with a marketing authorization for mRCC and that is why it was used in all patients of the study regardless of prognostic group or histologic type.

Results of this study concerning PFS (14 months) and OS (22 months) are consistent with literature data. In fact, PFS of patients treated with sunitinib as first line therapy of mRCC ranges generally from 8.2 to 14.2 months and OS varies from 18.4 to 32 months [18]-[20].

Most of AE reported in the literature were reported in patients of this study. These AE were mainly of grade 1 and 2, but severe toxicities (grade 3 and 4) were rarely observed. Indeed, more functional AE (asthenia, anorexia, vomiting, abdominal pain, and arthralgia), more mucocutaneous toxicity (hand foot syndrome (HFS), mucositis) and less biological disturbances (anemia, neutropenia, and liver function tests) were reported. On the other hand, the evaluation of the tolerance of sunitinib in patients of this study was based on retrospective data from the files of patients. This may explain why some toxicities mentioned in the literature, and which are not systematically checked, were not reported, such as thyroid dysfunction, hypophosphatemia, pancreatic reactions, erectile dysfunction.

Finally, some limitations should be noted. In fact, we were limited by two key points: the population size and the retrospective nature of the study. In fact, the number of patients did not allow carrying out analytical studies and therefore no conclusions concerning the response to treatment or survival depending on different sub groups were possible. Besides, patients of this study do not represent all patients treated for mRCC during the period of 
the study. In Tunisia only patients having a national health insurance and some wealthy patients can benefit from sunitinib, because of the high cost of the drug. Concerning the retrospective nature of the study, it was a limitation because some files had missing data especially for side effects, and even when reported, some details about grade and management were sometimes incomplete. Also, the biological tests such as liver, pancreatic and thyroid function tests were not performed systematically for all patients which could explain, as mentioned above, why the frequency of biological side effects was lower than that reported in the literature.

Despite these limitations, this study has the merit of being the first national multicenter work evaluating efficacy and tolerance of sunitinib in Tunisian patients with mRCC. Also, regarding findings related to OS, results of this study have the advantage of being associated only with the use of sunitinib since patients did not receive a second-line treatment, unlike most of other series in which patients were treated with two or three lines of targeted therapies, making the comparison of rates of OS relative to each product difficult.

\section{Conclusion}

In accordance with literature data, sunitinib in this study has showed a significant efficacy as a first-line treatment of metastatic and locally advanced RCC. Fatigue, anorexia, diarrhea, oral changes, skin toxicity and hypertension seemed to be the most clinically relevant toxic events. These side effects are usually reversible and do not require dose adjustments or interruptions.

\section{Acknowledgements}

The authors thank Doctor Mohamed Wassim Krir for his contribution in the writing and proof reading of the manuscript.

\section{Disclosure Policy}

The authors declare that there is no conflict of interest regarding the publication of this paper.

\section{References}

[1] Ljungberg, B., Campbell, S.C., Choi, H.Y., Jacqmin, D., Lee, J.E., Weikert, S., et al. (2011) The Epidemiology of Renal Cell Carcinoma. European Urology, 60, 615-621. http://dx.doi.org/10.1016/j.eururo.2011.06.049

[2] Pascual, D. and Borque, A. (2008) Epidemiology of Kidney Cancer. Advances in Urology, 782381. http://dx.doi.org/10.1155/2008/782381

[3] Lipworth, L., Tarone, R.E. and McLaughlin, J.K. (2006) Re: The Epidemiology of Renal Cell Carcinoma. Journal of Urology, 176, 2353-2358. http://dx.doi.org/10.1016/j.juro.2007.05.073

[4] Jemal, A., Siegel, R., Ward, E., Hao, Y., Xu, J., Murray, T., et al. (2008) Cancer Statistics, 2008. CA: A Cancer Journal for Clinicians, 58, 71-96. http://dx.doi.org/10.3322/CA.2007.0010

[5] Eggener, S.E., Yossepowitch, O., Pettus, J.A., Snyder, M.E., Motzer, R.J. and Russo, P. (2006) Renal Cell Carcinoma Recurrence after Nephrectomy for Localized Disease: Predicting Survival from Time of Recurrence. Journal of Clinical Oncology, 24, 3101-3106. http://dx.doi.org/10.1200/JCO.2005.04.8280

[6] Stewart, J.H., Buccianti, G., Agodoa, L., Gellert, R., McCredie, M.R., Lowenfels, A.B., et al. (2003) Cancers of the Kidney and Urinary Tract in Patients on Dialysis for End-Stage Renal Disease: Analysis of Data from the United States, Europe, and Australia and New Zealand. Journal of the American Society of Nephrology, 14, 197-207. http://dx.doi.org/10.1097/01.ASN.0000039608.81046.81

[7] Hoffmann, N.E., Gillett, M.D., Cheville, J.C., Lohse, C.M., Leibovich, B.C. and Blute, M.L. (2008) Differences in Organ System of Distant Metastasis by Renal Cell Carcinoma Subtype. Journal of Urology, 179, 474-477. http://dx.doi.org/10.1016/j.juro.2007.09.036

[8] Zini, L., Perrotte, P., Jeldres, C., Capitanio, U., Pharand, D., Arjane, P., et al. (2008) Nephrectomy Improves the Survival of Patients with Locally Advanced Renal Cell Carcinoma. BJU International, 102, 1610-1614. http://dx.doi.org/10.1111/j.1464-410X.2008.07917.x

[9] Margulis, V., Sanchez-Ortiz, R.F., Tamboli, P., Cohen, D.D., Swanson, D.A. and Wood, C.G. (2007) Renal Cell Carcinoma Clinically Involving Adjacent Organs: Experience with Aggressive Surgical Management. Cancer, 109, 20252030. http://dx.doi.org/10.1002/cncr.22629

[10] Patard, J.J., Baumert, H., Correas, J.M., Escudier, B., Lang, H., Long, J.A., et al. (2010) [Recommendations OncoUrology 2010: Kidney Cancer]. Progrès en Urologie, 20, S319-S339. 
http://dx.doi.org/10.1016/S1166-7087(10)70048-8

[11] Mejean, A., Correas, J.M., Escudier, B., de Fromont, M., Lang, H., Long, J.A., et al. (2007) [Kidney Tumors]. Progrès en Urologie, 17, 1101-1144. http://dx.doi.org/10.1016/S1166-7087(07)74782-6

[12] Audenet, F., Roupret, M. and Mejean, A. (2009) [Renal Cell Carcinoma and Antiangiogenic Agents: Ongoing Controversies Are Seeking Answers for Improvement of Therapeutic Management]. Progrès en Urologie, 19, 596-605. http://dx.doi.org/10.1016/j.purol.2009.05.009

[13] Mejean, A. and Lebret, T. (2008) [Prise en charge of metastatic renal carcinoma]. Progrès en Urologie, 18, S298-S308. http://dx.doi.org/10.1016/S1166-7087(08)74558-5

[14] Simon, C.J., Dupuy, D.E., Di Petrillo, T.A., Safran, H.P., Grieco, C.A., Ng, T., et al. (2007) Pulmonary Radiofrequency Ablation: Long-Term Safety and Efficacy in 153 Patients. Radiology, 243, 268-275. http://dx.doi.org/10.1148/radiol.2431060088

[15] Yan, T.D., King, J., Sjarif, A., Glenn, D., Steinke, K. and Morris, D.L. (2006) Percutaneous Radiofrequency Ablation of Pulmonary Metastases from Colorectal Carcinoma: Prognostic Determinants for Survival. Annals of Surgical Oncology, 13, 1529-1537. http://dx.doi.org/10.1245/s10434-006-9101-1

[16] Denys, A., Doenz, F., Qanadli, S.D. and Chevallier, P. (2005) [Radiofrequency Tumor Ablation: From the Liver to the Lung Passing by the Kidney]. Revue Médicale Suisse, 1, 1774-1778.

[17] Motzer, R.J., Hutson, T.E., Tomczak, P., Michaelson, M.D., Bukowski, R.M., Rixe, O., et al. (2007) Sunitinib versus Interferon Alfa in Metastatic Renal-Cell Carcinoma. New England Journal of Medicine, 356, 115-124. http://dx.doi.org/10.1056/NEJMoa065044

[18] Motzer, R.J., Hutson, T.E., Tomczak, P., Michaelson, M.D., Bukowski, R.M., Oudard, S., et al. (2009) Overall Survival and Updated Results for Sunitinib Compared with Interferon Alfa in Patients with Metastatic Renal Cell Carcinoma. Journal of Clinical Oncology, 27, 3584-3590. http://dx.doi.org/10.1200/JCO.2008.20.1293

[19] Gore, M.E., Hariharan, S., Porta, C., Bracarda, S., Hawkins, R., Bjarnason, G.A., et al. (2011) Sunitinib in Metastatic Renal Cell Carcinoma Patients with Brain Metastases. Cancer, 117, 501-509. http://dx.doi.org/10.1002/cncr.25452

[20] Motzer, R.J., Hutson, T.E., Cella, D., Reeves, J., Hawkins, R., Guo, J., et al. (2013) Pazopanib versus Sunitinib in Metastatic Renal-Cell Carcinoma. New England Journal of Medicine, 369, 722-731. http://dx.doi.org/10.1056/NEJMoa1303989

\section{Submit or recommend next manuscript to SCIRP and we will provide best service for you:}

Accepting pre-submission inquiries through Email, Facebook, LinkedIn, Twitter, etc.

A wide selection of journals (inclusive of 9 subjects, more than 200 journals)

Providing 24-hour high-quality service

User-friendly online submission system

Fair and swift peer-review system

Efficient typesetting and proofreading procedure

Display of the result of downloads and visits, as well as the number of cited articles

Maximum dissemination of your research work

Submit your manuscript at: http://papersubmission.scirp.org/ 